$7 / 93$

NASA Technical Memorandum

$$
106333 \text { errato Rec. }
$$

AIAA-93-1998

\title{
Development of Hypersonic Engine Seals: Flow Effects of Preload and Engine Pressures
}

Zhong Cai, Rajakkannu Mutharasan and Frank K. Ko

Drexel University

Philadelphia, Pennsylvania

and

Bruce M. Steinetz

NASA Lewis Research Center

Cleveland, Ohio

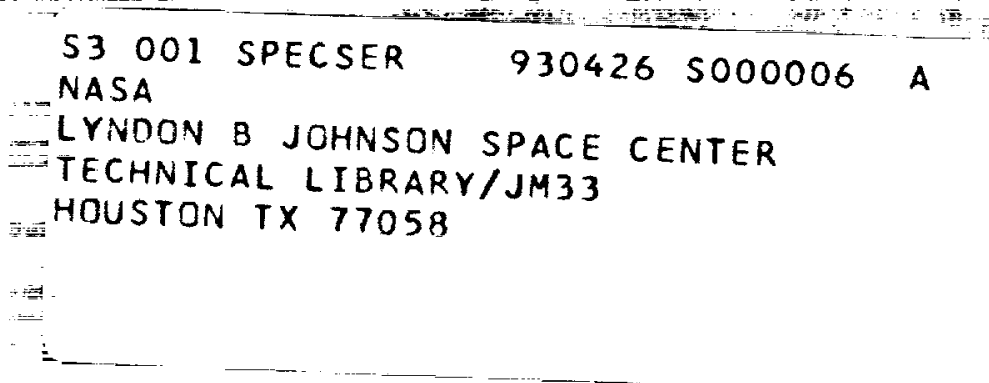

Prepared for the

29th Joint Propsulsion Conference and Exhibit cosponsored by the AIAA, SAE, ASME, and ASEE

- Monterey, California, June 28-30, 1993

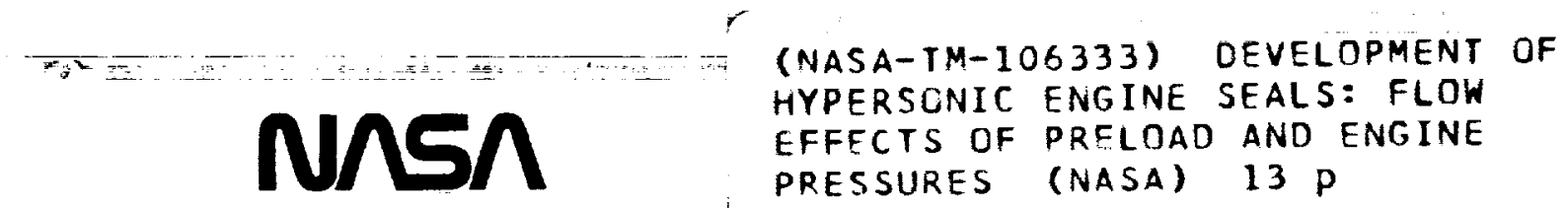

N94-27599 HYPERSCNIC ENGINE SEALS: FLOW EFFECTS OF PRFLOAD AND ENGINE PRESSURES (NASA) $13 \mathrm{P}$

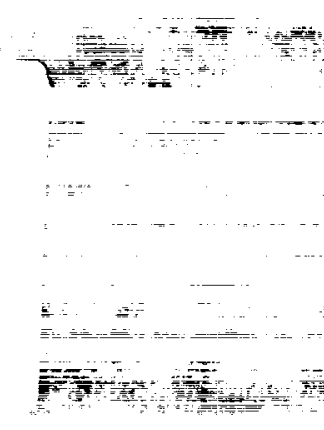




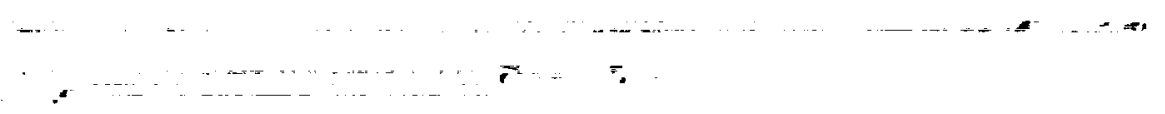

6

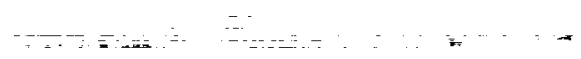

- ... .. -

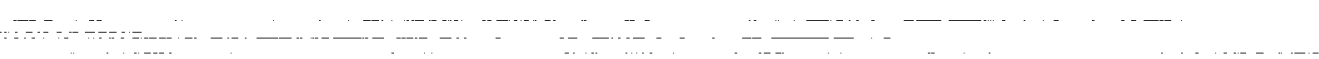

$\therefore-\therefore-1-1-1$

$=$

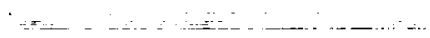

$+$
,$-1-1-1$
$+\cdots+-\cdots$
(n)
$x=-1=-$
$-1-1$

.

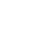


-

$-=$ 


\title{
Development of Hypersonic Engine Seals: Flow Effects of Preload and Engine Pressures
}

\author{
Zhong Cai $^{*}$, Rajakkannu Mutharasan ${ }^{\dagger}$, Frank K. Ko ${ }^{\ddagger}$ \\ Drexel University \\ Philadelphia, PA 19104
}

\author{
Bruce M. Steinetz ${ }^{\S}$ \\ NASA Lewis Research Center \\ Cleveland, $\mathrm{OH} 44135$
}

\begin{abstract}
A new type of engine seal is being developed to meet the needs of advanced hypersonic engines. A seal braided of emerging high temperature ceramic fibers comprised of a sheath-core construction has been selected for study based on its low leakage rates. Flexible, low-leakage, high temperature seals are required to seal the movable engine panels of advanced ramjet-scramjet engines either preventing potentially dangerous leakage into backside engine cavities or limiting the purge coolant flow rates through the seals. To predict the leakage through these flexible, porous seal structures as a function of preload and engine pressures, new analytical flow models are required. An empirical leakage resistance/preload model is proposed to characterize the observed decrease in leakage with increasing preload. Empirically determined compression modulus and preload factor are used to correlate experimental leakage data for a wide range of seal architectures. Good agreement between measured and predicted values are observed over a range of engine pressures and seal preload.
\end{abstract}

\section{NOMENCLATURE}

$\begin{array}{lll}\mathrm{A}_{\mathrm{C}} & = & \text { Cross sectional area of the seal } \\ \mathrm{A}_{\mathrm{y}} & = & \text { Yarn cross sectional area } \\ \mathrm{D}_{\mathrm{f}} & = & \text { Fiber diameter } \\ \mathrm{E}_{\mathrm{SI}} & = & \text { Seal compression modulus } \\ \mathrm{gc} & = & \text { Gravitational constant } \\ \mathrm{L} & = & \text { Seal length } \\ \dot{\mathrm{M}} & = & \text { Mass leakage rate } \\ \mathrm{M}_{\mathrm{W}} & = & \text { Molecular weight of gas } \\ \mathrm{N}_{\mathrm{C}} & = & \text { Number of yarns in the core } \\ \mathrm{N}_{\mathrm{S}} & = & \text { Number of yarns in the sheath } \\ \mathrm{P}_{\mathrm{e}} & = & \text { Engine pressure differential (psig) } \\ & & \text { (Pi }-\mathrm{P}_{\mathrm{o}} \text { ) }\end{array}$

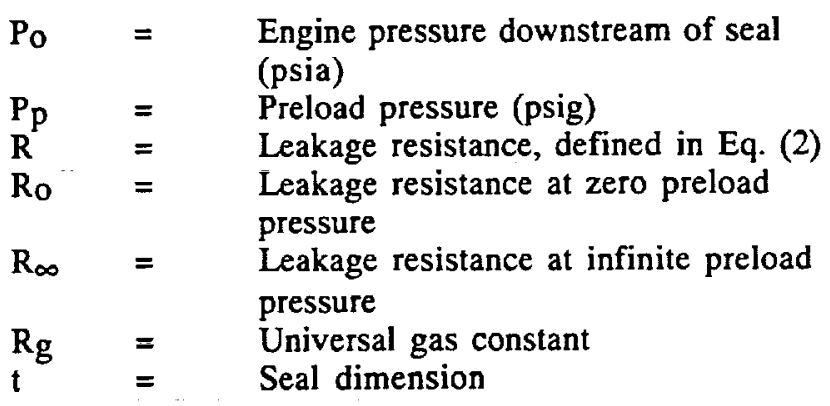

Greek:

$\begin{array}{lll}\alpha & = & \text { Preload factor } \\ \varepsilon & = & \text { Seal porosity } \\ \varepsilon_{0} & = & \text { Seal porosity at zero preload pressure } \\ \varepsilon_{\min } & = & \text { Seal minimum porosity at infinite } \\ \theta & & \text { preload pressure } \\ \mu & = & \text { Braiding angle } \\ \mu & =\text { gas viscosity }\end{array}$

Subscripts:

$\begin{array}{lll}\text { c } & = & \text { Fiber core } \\ \text { s } & = & \text { Braid sheath } \\ \text { sl } & = & \text { Seal }\end{array}$

\section{INTRODUCTION}

Ramjet-scramjet engines require sliding panel seals to prevent combustion gases from leaking past the articulating engine panels, similar to articulating panel seals of turbojet two-dimensional converging-diverging nozzles [1]. However, new seals are required for advanced hypersonic engines because of higher thermal loads and the need to seal larger engine sidewall distortions. As a point of comparison, turbojet nozzle seals developed under the augmented deflector exhaust nozzle program [2] used superalloy seals that sealed pressure differentials up to $30 \mathrm{psi}$, sealed sidewall distortions up to 0.030 in., and were cooled to $1200^{\circ} \mathrm{F}$.

Research Associate, Materials Engineering Dept.

$\dagger \quad$ Professor of Chemical Engineering

$\ddagger \quad$ Professor of Materials Engineering

$\S \quad$ Research Engineer, Structural Dynamics Branch, Member AIAA 
Hypersonic engine seals, however, are required to operate at higher temperatures $\left(1800-2000^{\circ} \mathrm{F}\right)$, seal high pressure differentials (up to $100 \mathrm{psi}$ ), and seal larger sidewall distortions (up to $0.150 \mathrm{in}$.), as described in [3].

A seal concept that shows promise of meeting these challenging demands is the braided ceramic rope seal being developed at NASA Lewis Research Center. The braided ceramic rope seal structure consists of a highdensity uniaxial core structure overbraided with an outer sheath for structural integrity, as shown in Fig. 1. Braided of emerging high-temperature ceramic fibers, this seal shows promise of operating hot and remaining flexible at temperatures up to $2000^{\circ} \mathrm{F}$. Active preload means, such as the cooled metal bellows as shown, are used to preload the seal against the adjacent sidewall. As one would expect, increasing seal preload increases seal flow resistance thereby limiting leakage flow through the seal.

Accompanying the development of these engine seals, NASA is also developing engine seal flow models to predict the seal leakage through these porous seal structures. These seal flow models can be used during the design process in one of two ways: 1) to predict performance losses associated with parasitic leakage through the seals; and 2) to predict purge coolant flow rates through these seals where ambient engine flow temperatures exceed the seal's operating temperature limit.

In an earlier paper [4] analyzing the seal leakage flow, mathematical models of leakage flow through the braided rope seals based on the Kozeny-Carman equation were proposed. The flow model enables prediction of gas leakage rate as a function of fiber diameter, seal porosity, gas properties, and pressure differential across the seal. Although the model predicts leakage rates satisfactorily, it does not account for changes in leakage rates at various lateral preload pressures.

The purpose of this article is to provide an analytical means of predicting the gas flow through these braided structures as a function of engine and preload pressures.

\section{THEORY}

Seal Leakage Resistance. The braided rope seal structure shown in Fig. 1 presents an effective flow barrier between the high pressure $\left(\mathrm{P}_{\mathrm{j}}\right)$ and low pressure $\left(\mathrm{P}_{\mathrm{o}}\right)$ sides of the seal. Ref. [4] provided the theoretical basis for modeling the one-dimensional flow through these seals based on the Kozeny-Carman equation with a fixed porosity $(\varepsilon)$, The mass flow for the seal structure was given as

$$
\frac{\dot{M}}{L}=\frac{P_{i}^{2}-P_{0}^{2}}{300\left(\mu R_{g} T / M_{w} g_{c}\right)\left(t L / A_{c}\right)\left[(1-\varepsilon)^{2} / \varepsilon^{3}(\phi D)^{2}\right]}
$$

The braided seal flow resistance was defined as the rate of the differences in the squares of the pressures (driving potential) to the mass flow rate as

$$
\mathrm{R}=\frac{\mathrm{P}_{\mathrm{i}}^{2}-\mathrm{P}_{0}^{2}}{\dot{\mathrm{M}} / \mathrm{L}}
$$

For simplicity in [4], $R$ was assumed to be independent of the applied pressure difference and the preload applied to the seal.

Experimental evidence has shown that the effective seal flow resistance is dependent upon both the preload pressure and the engine pressure differential. Using (1) and (2) above, the seal resistance is strongly dependent on the porosity as

$$
R=\frac{K}{\left(\phi D_{f}\right)^{2}} \frac{(1-\varepsilon)^{2}}{\varepsilon^{3}}
$$

where

$$
K=300\left(\frac{\mu R_{g} T}{M_{w} g_{c}}\right)\left(\frac{t L}{A_{c}}\right)
$$

As will be shown herein, the seal porosity and the seal resistance are dependent upon the engine and preload pressures.

Resistance Preload Model. Establishing an analytical relationship between compression stress and strain based on the mechanical behavior of the thousands of fibers contained in these seal structures and the seal porosity would be immensely complex. Further the resulting expression may not provide an engineering model useful in predicting the seal leakage dependence on engine pressures and preloads. First, the fiber core and braided sheath should be considered separately. Second, in the seal core, all fibers are supposed to be perfectly aligned in the length direction, and the assumption of "point contact" may not be valid. Third, at the very low porosity level, a high transverse stress will be required to further compress the fiber assembly, and the compression resistance due to deformation of individual fibers may need to be considered. Therefore, a simpler empirical approach is proposed to describe the relationship between the seal leakage resistance, and the preload and engine 
pressures. Since both $P_{p}$ and $P_{e}$ change the seal resistance, both should be considered in evaluating seal performance. Expressing such an idea quantitatively gives

$R=R_{0}+\left(R_{\infty}-R_{0}\right)\left\{1-\exp \left[-\left(\alpha P_{p}+(1-\alpha) P_{e}\right) / E_{s l}\right]\right\}$

where $R$ is the leakage resistance at a given preload pressure $P_{p}$ and engine pressure $P_{e}, R_{0}$ is the leakage resistance at zero preload pressure $P_{p}=0$ psig and "nearzero" engine pressure $P_{e} \approx 0 p s i g, R_{\infty}$ is the maximum resistance at $P_{p}=\infty$ and $P_{e}=\infty$. The parameter $E_{S I}$ is defined as the seal compression modulus, and $\alpha$ is a weighting factor of preload pressure contribution to the seal compression (abbreviated as preload factor). The expression captures the characteristics of the resistancepreload relationship observed in the experiments, namely the leakage resistance increases at a decreasing rate with increasing preload pressure. The leakage response behavior is governed by the seal compression modulus and the preload factor. The seal compression modulus and the preload factor, in turn, are governed by seal structure and the nature of the fiber material, and can be determined experimentally for a particular type of seal.

Letting $\varepsilon_{0}$ be the seal porosity with zero preload pressure and zero engine pressure, the leakage resistance at $P_{p}=$ 0 psig and $P_{e}=0$ psig can be estimated as

$$
R_{0}=\frac{K}{\left(\phi D_{f}\right)^{2}} \frac{\left(1-\varepsilon_{0}\right)^{2}}{\varepsilon_{0}^{3}}
$$

When subjected to a hypothetical infinite preload, the seal is most tightly packed, and its porosity approaches the lowest possible value, denoted as $\varepsilon_{\min }$. An analysis of the seal micro-structure shows that the lowest seal porosity is 0.093 , based on the architecture of hexagonal packing of cylindrical fibers. The maximum resistance can then be determined as

$$
R_{\infty}=\frac{K}{\left(\phi D_{f}\right)^{2}} \frac{\left(1-\varepsilon_{\min }\right)^{2}}{\varepsilon_{\min }^{3}}
$$

With a rearrangement of the terms, equation (4) can be transformed to a linear equation for compressional modulus $E_{\mathrm{Sl}}$ and the preload factor $\alpha$ as

$$
\frac{P_{e}}{\ln \left(\frac{R_{\infty}-R_{o}}{R_{\infty}-R}\right)}=\alpha \frac{P_{e}-P_{p}}{\ln \left(\frac{R_{\infty}-R_{o}}{R_{\infty}-R}\right)}+E_{s l}
$$

Therefore a linear regression method can be used to determine $E_{\mathrm{Sl}}$ and $\alpha$ for the seal samples by using the experimental data $\left(R, P_{e}, P_{p}\right)$. If the proposed model can describe the seal leakage response correctly, then experimental data will lie on a straight line in a transformed plot using equation (7). Graphical observations indicate there is some extent of data scattering for different seals. Selection of a certain preload pressure range to perform linear regression calculation can give more accurate predictions within the interested pressure range.

In the calculation the initial seal resistance $R_{0}$ is obtained from (5) with the $\mathrm{K}$ from equation (3). The geometry transformation factor $\phi$ is chosen as 1.5 [4]. The fiber diameter $D_{f}$ and the initial seal porosity $\varepsilon_{0}$ are shown in Table 1 . Similarly the maximum resistance $R_{\infty}$ is calculated from (6). The minimum seal porosity used in the calculation is $\varepsilon_{\min }=0.093$.

\section{EXPERIMENTS}

Seal specimens used for this investigation were fabricated using a dense uniaxial core overbraided with several layers of 2-D braided sheath as indicated in Fig. 1. Seals were made of either E-glass fibers (seals $A 1$, B1, D1, G1) or Nextel ceramic fibers (M6a, M6b, M6c). A summary of properties important to the current investigations are given in Table 1. More detailed architectural information for the E-glass and ceramic seals can be found in [4] and [5] respectively.

Flow Measurement. Seal specimens were mounted in a specially developed test fixture shown in Fig. 2, and were leak tested at room temperature under various inlet pressure conditions in the range of 5 to $80 \mathrm{psig}$. The pressure upstream of the seal was varied and the resulting leakage of gas (either air or helium) was measured. Lateral preloads were applied uniformly to the back of the seal with an inflatable rubber diaphragm at pressures from 0 to 240 psig. The flow resistance of the seal was computed from the ratio of the difference of squares of absolute pressures over the mass leakage rate using (2).

Porosity. Calculation of an initial resistance $R_{0}$ requires an initial porosity $\varepsilon_{0}$. The initial porosity used for the Eglass specimens fabricated for earlier studies were calculated using the following equation derived from 
fiber packing within braided structures as

$$
\varepsilon_{0}=1-\frac{A_{y}\left(N_{c}+N_{s} / \cos \theta\right)}{t^{2}}
$$

where $N_{c}$ and $N_{S}$ are the number of core and sheath yarns, $A_{y}$ is the yarn cross sectional area, and $t^{2}$ is the cross sectional area of the installed seal.

Porosity for the Nextel ceramic fiber seals were determined using a hybrid approach to better reflect the initial installed porosity of the seal. In this approach, samples of the seals were placed in a 0.5 inch wide channel simulating the seal channel. This assembly was placed open side pointing-up, in an Instron compression tester that applied increasing loads to the seal. Prior to loading, the initial seal height is measured. As the compression bar contacts the seal no significant load is measured. After the compression bar travels down some distance, the compressive load is measured. The position corresponding to this point of initial resistive load is also measured. The initial porosity is then calculated.

Porosity determined using the above method are listed for each of the seals in Table 1.

\section{RESULTS AND DISCUSSION}

Leakage Resistance Pressure Dependence. Seal leakage resistance increases with increasing preload pressure and increasing engine pressure. Seal leakage resistance calculated with equation (2) are plotted for seals $A 1$ and G1 in Fig. 3 demonstrating these trends. This behavior is typical of all of the seals examined.

Another observation made from Fig. 3 is that leakage resistance increases at a decreasing rate at high engine and preload pressure. In other words the rate at which resistance increases slows as the seals reaches lower porosity levels. This observation is the basis for the logarithmic form of the resistance preload model used in these current analyses.

$\mathrm{B}_{0}$ and $\mathrm{R}_{\infty}$ Calculation. Initial $\mathrm{R}_{\mathbf{0}}$ and the maximum resistance $R_{\infty}$ are required in using the proposed resistance preload model. In the proposed model the seal resistance at any preload and engine pressure $R$ must be between the two limits of $R_{0}<R<R_{\infty}$. $R_{\infty}$ is calculated using the minimum porosity $\varepsilon_{\min }=0.093$ in equation (6), for the test gas being considered. The initial resistance $R_{0}$ is calculated using $\varepsilon_{0}$ found using techniques mentioned above and equation (5). The results of these calculations are given in Table $2 a$ for the E-glass seals and Table $3 a$ for the Nextel seals.
Correlation in Transformed Coordinates. The two parameters required for the resistance preload model to correlate the leakage data are the preload factor $\alpha$ and the seal compression modulus $E_{s l}$. These parameters are evaluated by plotting the leakage data on transformed coordinates according to equation (7). Ideally the data should fall on a straight line with a slope corresponding to the preload factor $\alpha$ and an intercept corresponding to the compression modulus $\mathrm{E}_{\mathrm{sl}}$.

The results of these calculations are plotted in Fig. 4 for seals A1, B1, D1, and G1. Except for the zero preload pressures, the data fall on a general trend line. Using linear regression, the slope and intercept of this general trend line are the values used for subsequent analyses and are given in Table $2 b$ for the E-glass seals. Similar exercises for the Nextel seals result in preload factors and compression moduli that are given in Table $3 \mathrm{~b}$.

In Fig. 4 the zero preload pressure data did not collapse onto the general trend line for the E-glass seals, though the slope of the line agreed reasonably well with the general trend line. This observation indicates that the final correlation is expected to be better at non-zero preloads where the seal is being slightly compacted.

Final Correlation. After determining the required parameters, including $R_{0}, R_{\infty}, \alpha$, and $E_{s l}$, one is able to predict the seal leakage as a function of preload pressure, engine pressure, and gas type. The required parameters are substituted into equation (4) to determine the seal resistance $R$. With this $R$ the mass flow rate can be evaluated for a given pressure differential using equation (2).

The results of these exercises for two E-glass seals A1 and G1 are shown in Figures 5 and 6 for air flow, showing excellent agreement between measured and predicted leakage rates over the range of engine pressure differential examined. Similar agreement was observed for other E-glass seals.

A comparison between predicted and measured leakage results for the Nextel seals M6a, M6b, and M6c are given in Figures 7-9. The agreement between predicted and measured results is again very good for both tested gases, air and helium.

\section{SUMMARY}

A semi-empirical model has been presented for predicting leakage rates of braided rope engine seals as a function of preload pressure, engine pressure, and test gas. The model builds on previous work providing for an increasing seal flow resistance with increasing seal 
preload pressure and engine pressure. The logarithmic form of the resistance preload model characterize the observed variation of the seal leakage resistance with increasing preload and engine pressures using a two term correlation. The preload factor provides a measure of the relative effects of preload and engine pressures on seal leakage. The seal compression modulus gauges the seal compressibility. The higher the compression modulus, the less the seal is deformed by transverse compression, and the less the leakage resistance is affected by the applied pressures. Correlation between the resistance preload model predictions and measured data is excellent for for a wide range of seal types (E-glass and ceramic), preload and engine pressures, and test gases (helium and air) examined.

\section{ACKNOWLEDGEMENT}

The authors wish to thank Xiaoming Tao, Susan Marr, Guang-Wu Du, Hon Wong, Dan Luu, and John McKelvie for their help in the seal design, fabrication, and testing. This project is funded by NASA Lewis Research Center

\section{REFERENCES}

1. Kuchar, A.D., "Variable Convergent-Divergent Exhaust Nozzle Aerodynamics", Aircraft Propulsion System Technology and Design, edited by G.C. Oates, AIAA, Washington, DC, 1989, pp.301-338.

2. Anon., "Advanced V/STOL Propulsion Component Development. Vol. 1: Nozzle/Deflector. Final Report", Aircraft Engine Group, General Electric Co., R77AEG441-VOL. 1, Cincinnati, OH, Aug. 1977.

3. Steinetz, B.M., "Evaluation of an Innovative High Temperature Ceramic Wafer Seal for Hypersonic Engine Applications", NASA TM-105556, February, 1992.

4. Mutharasan, R., Steinetz, B. M., Tao, X. M., and Ko., F., "Development of Braided Rope Seals for Hypersonic Engine Applications, Part II: Flow Modeling", paper presented at 27th Joint Propulsion Conference (AIAA/SAE/ASME), Paper No. AIAA-912495, June 1991.
5. Steinetz, B.M., DellaCorte, C., Machinchick, M., Mutharasan, R., Du, G., Ko, F., Sirocky, P.J., and Miller, J.H., "High Temperature Dynamic Engine Seal Technology Development", NASA TM-105641, 1992.

Table 1. Seal specimen information

\begin{tabular}{|l|c|c|c|}
\hline $\begin{array}{c}\text { Specimen } \\
\text { (Material) }\end{array}$ & $\begin{array}{c}\text { Seal } \\
\text { porosity }\end{array}$ & $\begin{array}{c}\text { Fiber } \\
\text { diameter } \\
(\mathrm{mm})\end{array}$ & $\begin{array}{c}\text { Fiber } \\
\text { modulus } \\
\left(\mathrm{x} 10^{6} \mathrm{psi}\right)\end{array}$ \\
\hline A1 (E-glass) & $0.48^{\mathrm{a}}$ & 10 & 10.5 \\
B1 (E-glass) & $0.48^{\mathrm{a}}$ & 10 & 10.5 \\
D1 (E-glass) & $0.42^{\mathrm{a}}$ & 10 & 10.5 \\
G1 (E-glass) & $0.45^{\mathrm{a}}$ & 10 & 10.5 \\
M6a (Nextel550) & $0.562^{\mathrm{b}}$ & 12 & 27.0 \\
M6b (Nextel 440) & $0.572^{\mathrm{b}}$ & 12 & 27.0 \\
M6c (Nextel 312) & $0.515^{\mathrm{b}}$ & 12 & 21.7 \\
\hline
\end{tabular}

a: Calculated porosity values [4].

b: Instron measured porosity values.

Table 2a: Resistance $\mathbf{R}_{\mathbf{0}}$ and $\mathbf{R}_{\infty}$ for seals A1, B1, D1, and $\mathrm{G} 1$

\begin{tabular}{|c|c|c|}
\hline Seal & $\begin{array}{c}R_{0} \\
\left(\operatorname{psia}^{2} \cdot s \cdot f t / h\right)\end{array}$ & $\begin{array}{c}R_{\infty} \\
\left(\mathrm{psia}^{2} \cdot \mathrm{s} \cdot \mathrm{ft} / \mathrm{lb}\right)\end{array}$ \\
\hline $\mathrm{A} 1$ & 13790 & \multirow{4}{*}{5768261} \\
\hline B1 & 13790 & \\
\hline D1 & 25609 & \\
\hline G1 & 18722 & \\
\hline
\end{tabular}

Table 2b: Compression modulus and preload factor for seals $A 1, B 1, D 1$, and $G 1$

\begin{tabular}{|c|c|c|}
\hline Seal & $\begin{array}{c}\text { Preload factor } \\
\alpha \\
\text { (air) }\end{array}$ & $\begin{array}{c}\text { Compression } \\
\text { Modulus Esl } \\
\text { (psi) } \\
\text { (air) }\end{array}$ \\
\hline A1 & 0.41 & 700 \\
\hline B1 & 0.70 & 1150 \\
\hline D1 & 0.58 & 760 \\
\hline G1 & 0.61 & 500 \\
\hline
\end{tabular}


Table 3a: Resistance parameters $R_{0}$ and $R_{\infty}$ for M6 series seals

\begin{tabular}{|c|c|c|c|c|}
\hline Seal & $\begin{array}{c}R_{0}(a i r) \\
\left(\mathrm{psia}^{2} \cdot s \cdot f t / b\right)\end{array}$ & $\begin{array}{c}\mathrm{R}_{\infty}(\mathrm{air}) \\
\left(\mathrm{psia}{ }^{2} \cdot \mathrm{s} \cdot \mathrm{ft} / \mathrm{lb}\right)\end{array}$ & $\begin{array}{l}\mathrm{R}_{\mathrm{o}} \text { (helium) } \\
\left(\mathrm{psia}^{2} \cdot \mathrm{s} \cdot \mathrm{ft} / \mathrm{lb}\right)\end{array}$ & $\begin{array}{l}R_{\infty} \text { (helium) } \\
\left(\mathrm{psia}^{2} \cdot \mathrm{s} \cdot \mathrm{ft} / \mathrm{lb}\right)\end{array}$ \\
\hline M6a & 4233 & \multirow{3}{*}{4005714} & 33375 & \multirow{3}{*}{31582673} \\
\hline M6b & 3834 & & 30226 & \\
\hline M6c & 6745 & & 53180 & \\
\hline
\end{tabular}

Table 3b: Compression modulus $E_{\mathrm{Sl}}$ and preload factor $\alpha$ for M6 series seals

\begin{tabular}{|c|c|c|c|c|}
\hline \multirow{2}{*}{ Seal } & \multicolumn{2}{|c|}{ Air } & \multicolumn{2}{c|}{ Helium } \\
\cline { 2 - 5 } & $\alpha$ & $\mathrm{E}_{\text {sl }}$ (psi) & $\alpha$ & $\mathrm{E}_{\text {Sl }}$ (psi) \\
\hline M6a & 0.20 & 2000 & 0.24 & 3810 \\
\hline M6b & 0.20 & 1600 & 0.23 & 2940 \\
\hline M6c & 0.26 & 1360 & 0.27 & 2520 \\
\hline
\end{tabular}

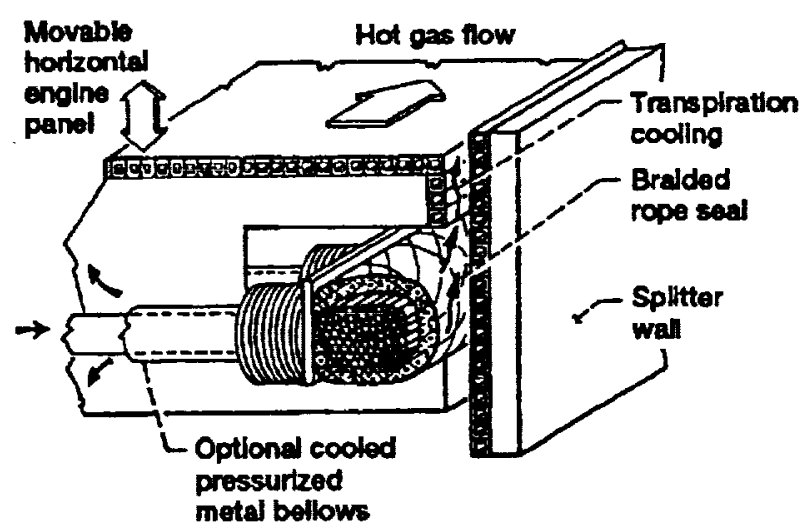

Fig. 1. Cross section of proposed engine seal. 


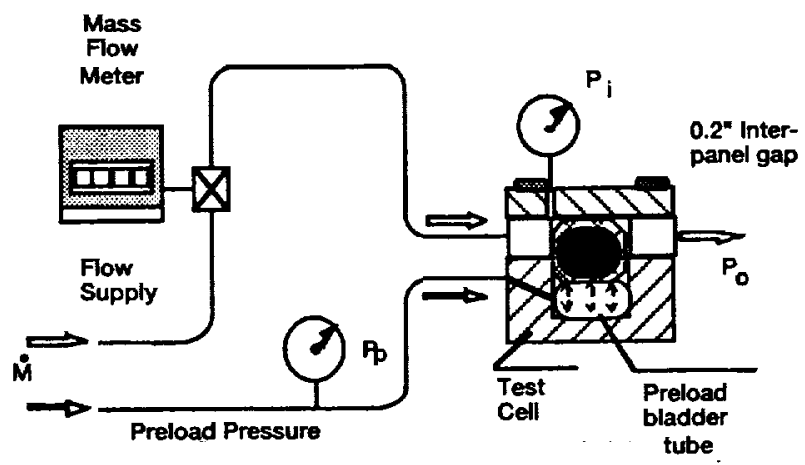

Fig. 2. Schematic of room temperature experimental apparatus.

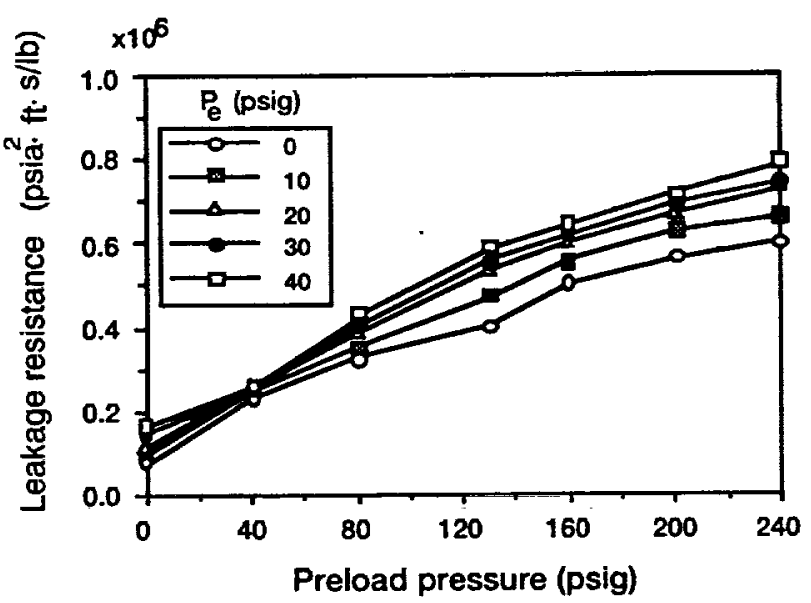

(a) Seal A1

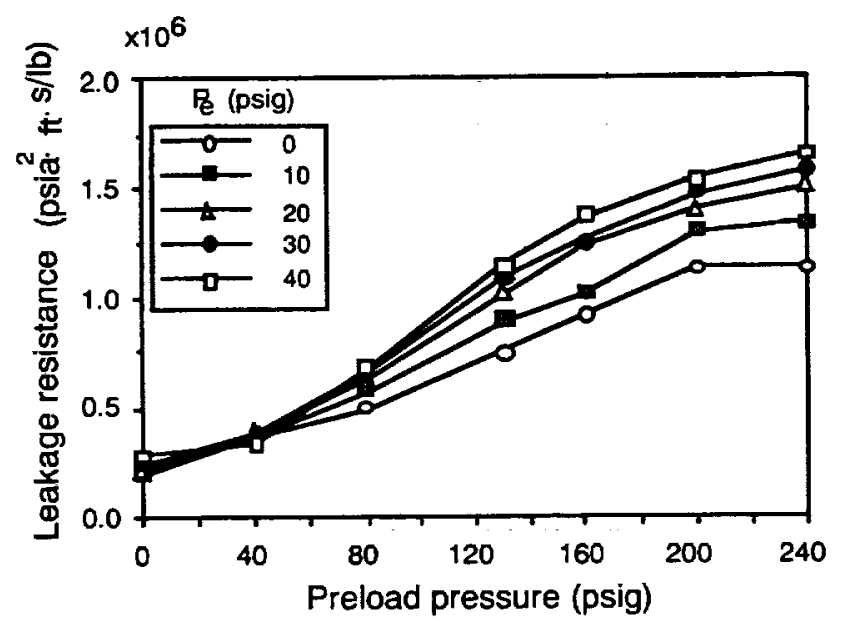

(b) Seal G1

Fig. 3. Effect of preload and engine pressure on seal leakage resistance (air). 

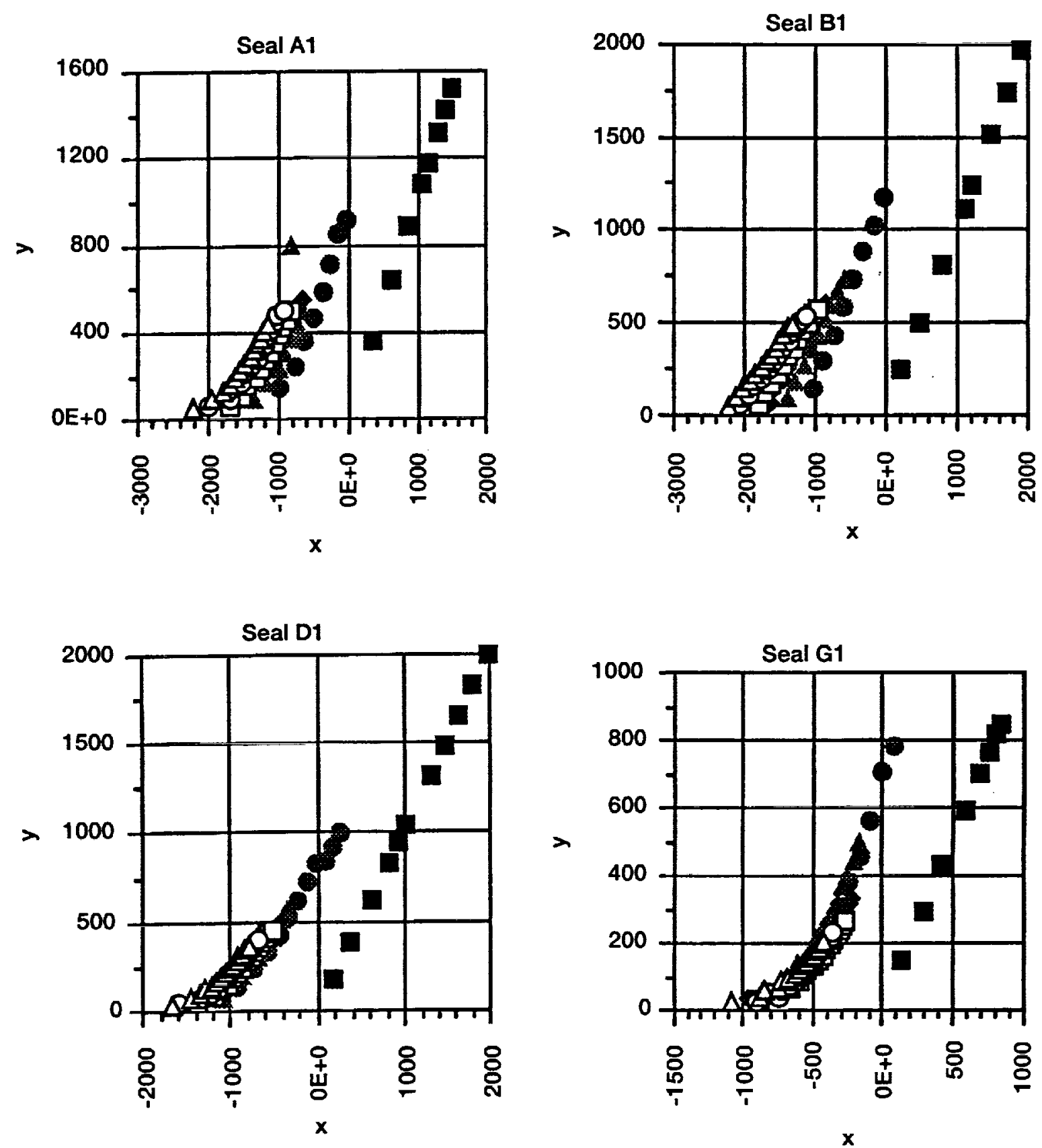
a $P p=0 p s i \quad \triangle P p=80 p s i \square P p=160 p s i \triangle P p=240 p s i$
- $P p=40 p s i ~ • P p=130 p s i \quad P p=200 p s i$

Fig. 4. Seal leakage data plotted on transformed coordinates to obtain preload factor $\alpha$ (slope) and seal compression modulus $\mathrm{E}_{\mathrm{Sl}}$ (intercept). 


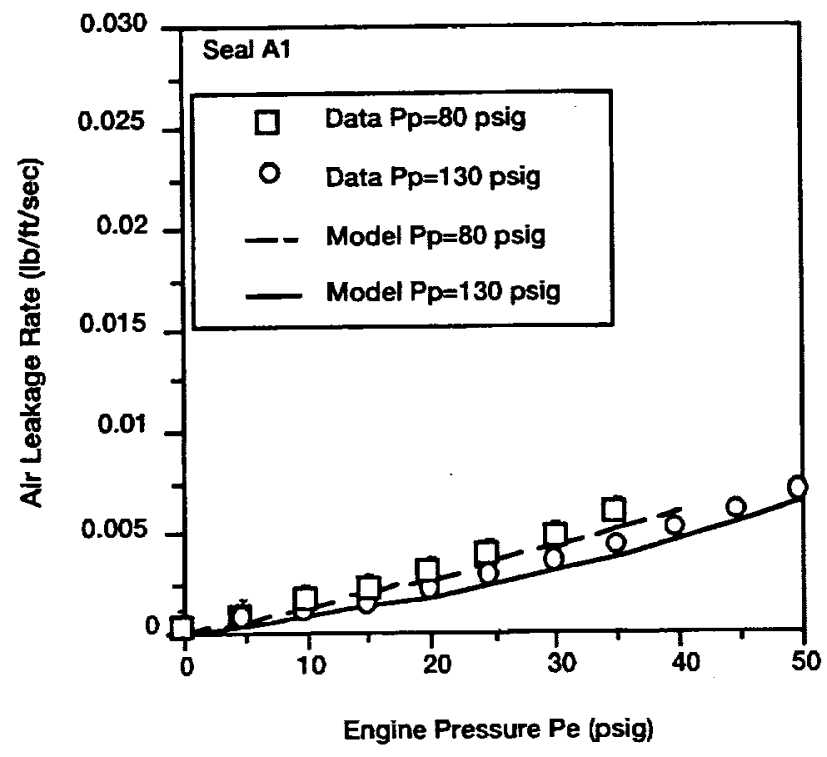

Fig. 5. Seal A1: Measured air leakage rates versus pressure drops (symbols) compared to predictions (lines).

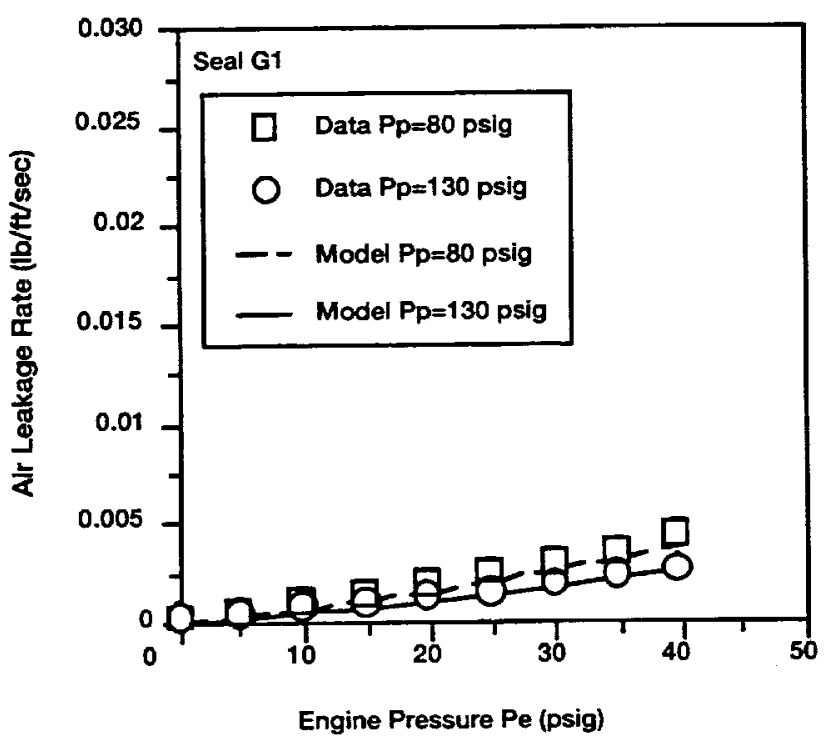

Fig. 6. Seal G1: Measured air leakage rates versus pressure drops (symbols) compared to predictions (lines)

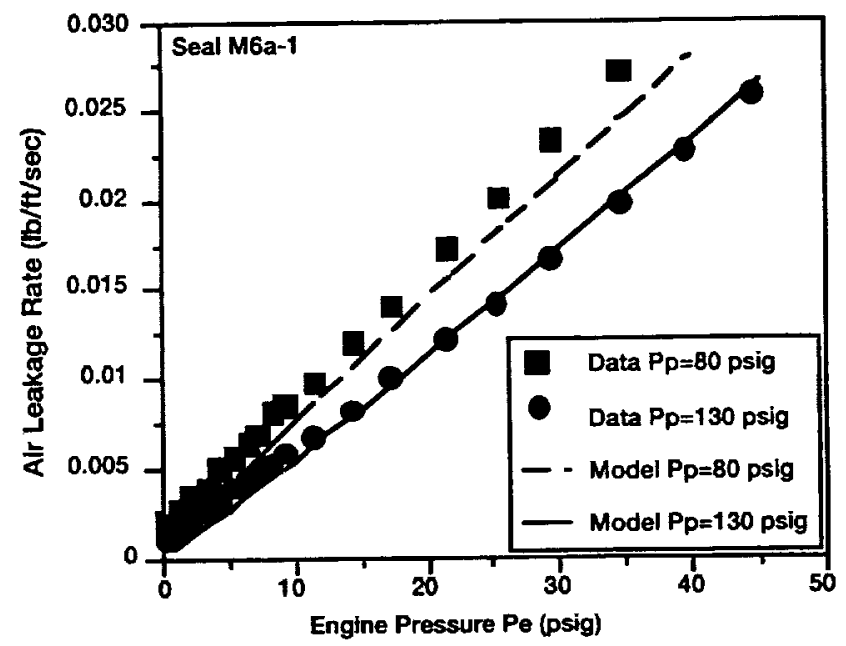

(a) Ajr

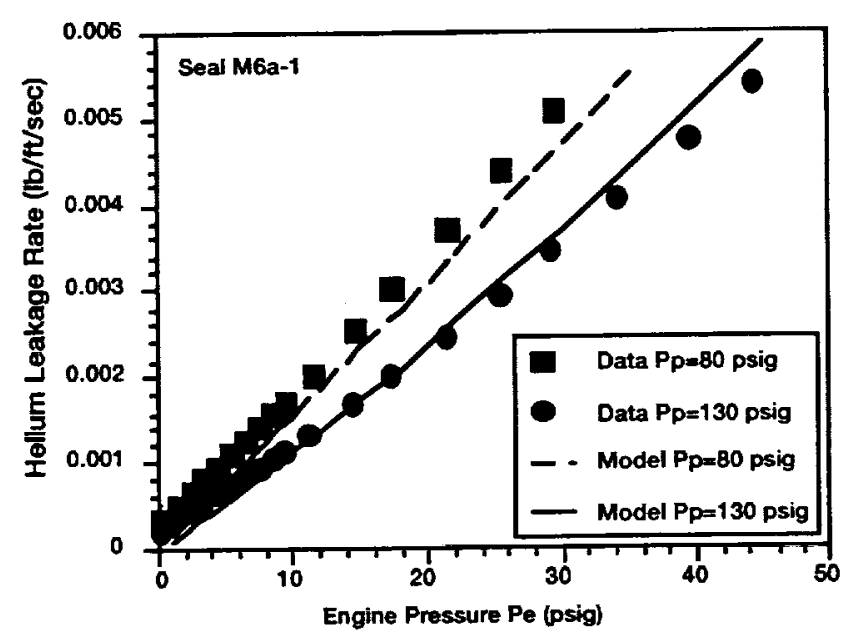

(b) Helium

Fig. 7: Seal M6a-1: Measured leakage rates versus pressure drops (symbols) compared to predictions (lines). 


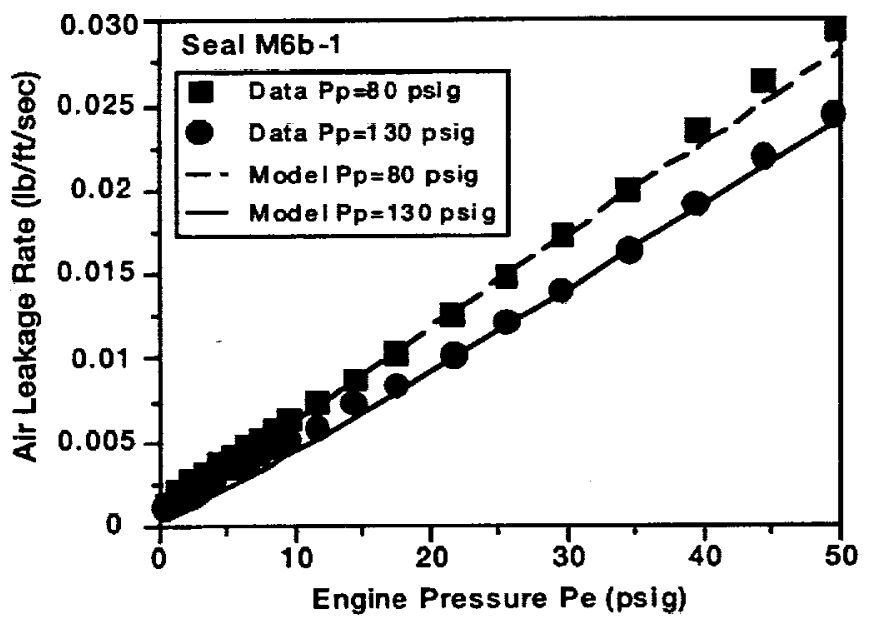

(a) Air

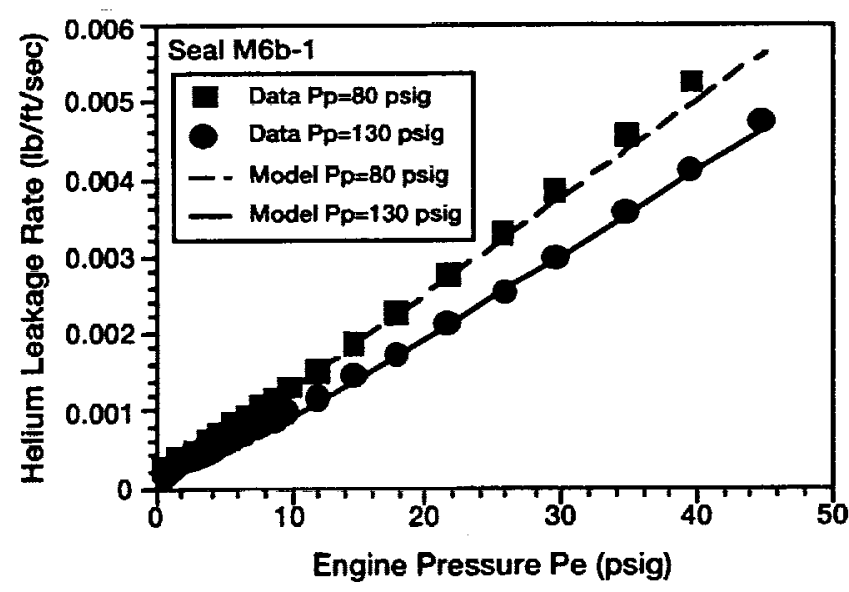

(b) Helium

Fig. 8: Seal M6b-1: Measured leakage rates versus pressure drops (symbols) compared to predictions (lines).

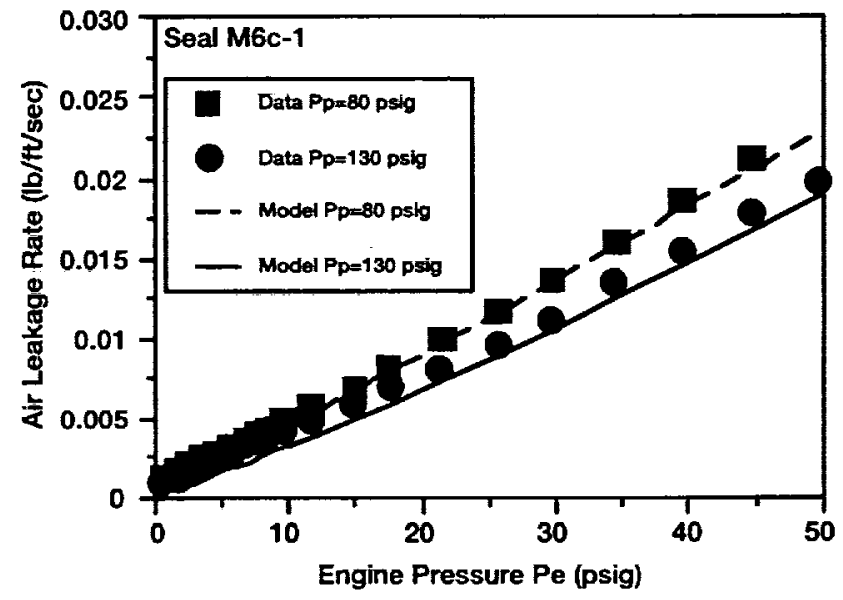

(a) Air

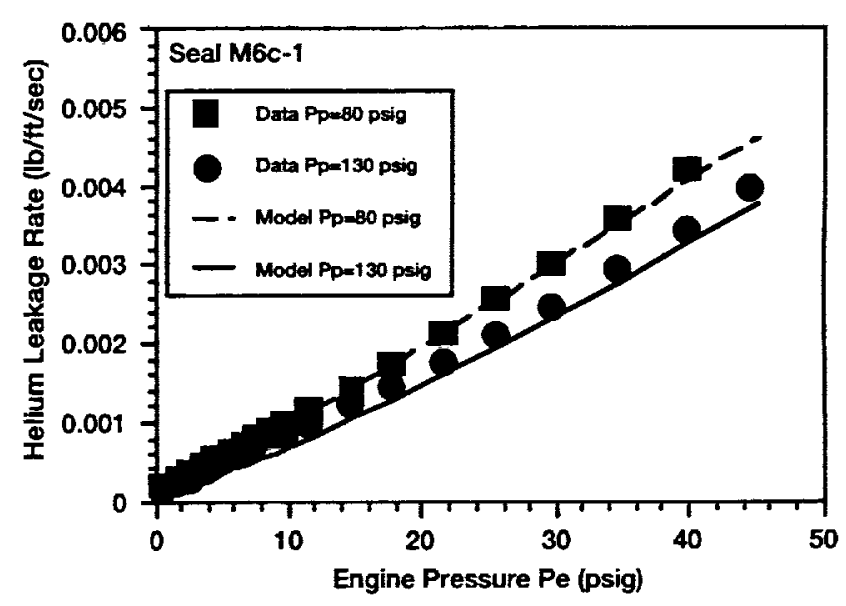

(b) Helium

Fig. 9: Seal M6c-1: Measured leakage rates versus pressure drops (symbols) compared to predictions (lines). 


\section{REPORT DOCUMENTATION PAGE}

Public reporting burden for this collection of information is estimated to average 1 hour per response, Including the time for reviewing instructions, searching existing data sources, gathering and maintaining the data needed, and completing and reviewing the collection of information. Send conments regarding this burden estimate or any other aspect of this collection of information, including suggestions for reducing this bufden, to Washington Headquarters Services, Directorate for intormation Operations and Reports, 20503 .

\begin{tabular}{|l|c|c|}
\hline 1. AGENCY USE ONLY (Leave blank) & $\begin{array}{c}\text { 2 REPOAT DATE } \\
\text { April } 1993\end{array}$ & $\begin{array}{r}\text { 3. REPORT TYPE AND DATES COVERED } \\
\text { Technical Memorandum }\end{array}$ \\
\hline
\end{tabular}

\section{TITLE AND SUBTITLE}

Development of Hypersonic Engine Seals: Flow Effects of Preload and Engine Pressures

6. AUTHOR(S)

Zhong Cai, Rajakkannu Mutharasan, Frank K. Ko, and Bruce M. Steinetz

\section{FUNDING NUMBERS}

WU-763-22-41
8. PERFORMING ORGANIZATION REPORT NUMBER

E-7400

National Aeronautics and Space Administration

Lewis Research Center

Cleveland, Ohio 44135-3191

10. SPONSORING/MONTTORING AGENCY REPORT NUMBER

National Aeronautics and Space Administration

Washington, D.C. 20546-0001

NASATM- 106333

11. SUPPLEMENTARY NOTES

Prepared for the 29th Joint Propuslion Conference and Exhibit cosponsored by the AIAA, SAE, ASME, and ASEE, Monterey, California, June 28-30, 1993. Zhong Cai, Rajakkannu Mutharasan and Frank K. Ko, Drexel University, Philadelphia, Pennsylvania, 19104 and Bruce M. Steinetz, NASA Lewis Research Center. Responsible person, Bruce M. Steinetz, (216) 433-3302.

12a. DISTRIBUTION/AVAILABILITY STATEMENT

12b. DISTRIBUTION CODE

Unclassified - Unlimited

Subject Category 37

\section{ABSTRACT (Maximum 200 words)}

A new type of engine seal is being developed to meet the needs of advanced hypersonic engines. A seal braided of emerging high temperature ceramic fibers comprised of a sheath-core construction has been selected for study based on its low leakage rates. Flexible, low-leakage, high temperature seals are required to seal the movable engine panels of advanced ramjet-scramjet engines either preventing potentially dangerous leakage into backside engine cavities or limiting the purge coolant flow rates through the seals. To predict the leakage through these flexible, porous seal structures as a function of preload and engine pressures, new analytical flow models are required. An empirical leakage resistance/preload model is proposed to characterize the observed decrease in leakage with increasing preload. Empirically determined compression modulus and preload factor are used to correlate experimental leakage data for a wide range of seal architectures. Good agreement between measured and predicted values are observed over a range of engine pressures and seal preloads.

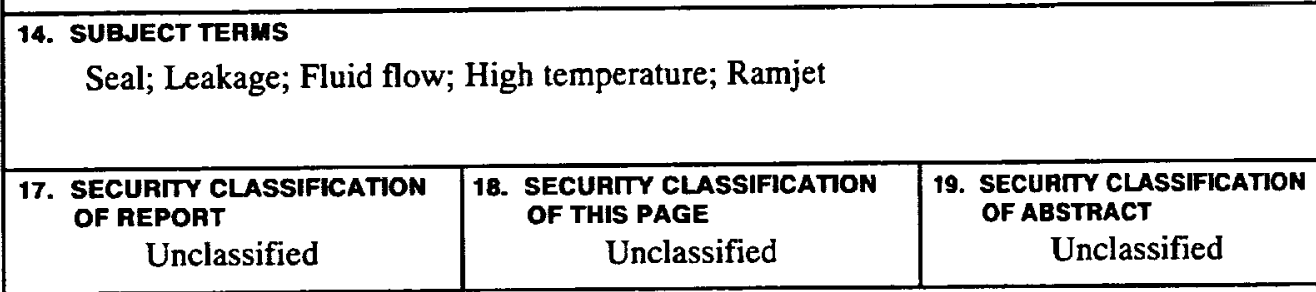


